* Mestranda em Direito pelo Programa de Pós-Graduação em Direito da Universidade Federal de Santa Maria (UFSM). Bacharel em direito pelo Centro Universitário Franciscano (UNIFRA). Advogada. Membro do Núcleo de Pesquisa em Direito Constitucional na UFSM.

mah.marilia@yahoo.com.br

** Pós-doutorado em andamento na Pontifícia Universidade Católica do Rio Grande do Sul (PUCRS). Doutora em Direito Público pela Universidade do Vale do Rio dos Sinos (UNISINOS). Mestre em Direito Público pela Universidade de Santa Cruz do Sul (UNISC). Graduada em Direito pela Universidade Federal de Santa Maria (UFSM). Professora do Programa de Pós-Graduação em Direito da UFSM. Professora Adjunta do Departamento de Direito da UFSM. Membro do Conselho Nacional de Pesquisa e Pós-Graduação em Direito (CONPEDI) e da Associação Brasileira do Ensino do Direito (ABEDI). Coordenadora do Núcleo do Direito Constitucional (NDC) da Universidade Federal de

\section{O Direito À Inclusão Digital: O Papel da Cidadania Online em Matéria Ambiental para a Construção de uma Democracia DireTA}

The Right to Digital Inclusion: the Role OF CitIZENSHIP ONLINE IN ENVIRONMENTAL MatTers to BiUlding a DIRECT DEMOCRACY

\section{Marília do Nascimento Pereira* Valéria Ribas do Nascimento**}

Como citar: PEREIRA, Marília do Nascimento. NASCIMENTO, Valéria Ribas do. O direito à inclusão digital: o papel da cidadania online em matéria ambiental para a construção de um democracia direta. Revista do Direito Público, Londrina, v. 12, n. 2, p. 130-154, ago. 2017. DOI: $10.5433 / 1980-511 X .2017 \mathrm{v} 12 \mathrm{n} 2 \mathrm{p} 130$

Resumo: O presente estudo visa discutir acerca do papel da cidadania digital para a efetivação da dimensão jurídico-política da sustentabilidade, em especial, o resguardo do direito fundamental à democracia. Nesse cenário, pretende-se observar como a cidadania vem sendo influenciada pelas novas tecnologias, com vistas a reformular o papel do indivíduo na sociedade dando possibilidade de participação mais ativa em decisões governamentais no que tange ao impulsionamento de questões ambientais. Para tal, utiliza-se do método de abordagem hipotético -dedutivo, tentando 
verificar se o instrumento virtual tem feito avançar nos ideais democráticos de participação, através do exercício de uma cidadania participativa. Elencouse também o método de procedimento monográfico analisando casos concretos de participação em matéria ambiental. Em sede de conclusão, pretende-se demonstrar como a cidadania digital pode ser manejo inovador em questões de sustentabilidade, revelando um novo paradigma para a democracia participativa.

Palavras-chave: Cidadania online. Questões ambientais. Democracia participativa.

Abstract: This study aims to discuss about the role of digital citizenship for effective legal and political dimension of sustainability, in particular the safeguarding of the fundamental right to democracy. In this scenario, we intend to observe how citizenship has been influenced by new technologies, in order to reshape the individual's role in society giving possibility of more active participation in government decisions regarding the boosting of environmental issues. To do this, we use the hypothetical -dedutivo method of approach, trying to verify that the virtual instrument has made progress in democratic ideals of participation, through the exercise of a participative citizenship. It is also listed out the monographic procedure method of
Santa Maria (UFSM). valribas@terra.com.br 
analyzing specific cases of participation in environmental matters. In place of conclusion, it is intended to demonstrate how digital citizenship can be innovative management in sustainability issues, revealing a new paradigm for participatory democracy.

Key-words: Online citizenship. Environmental issues. Participatory democracy. 


\section{INTRODUÇÃO}

O direito não apenas constrói as bases de uma sociedade e seu regramento, mas é moldado pelas práticas dos indivíduos, os quais provocam suas transformações ante a evolução da humanidade e os contornos da vida social. As profundas alterações nas noções de participação do ser humano engajado nas lutas sociais são pano de fundo para a construção de um direito mais igual e condizente com as vontades do povo. Sendo assim, as lutas sociais ganham especial importância nos mais variados assuntos, e provocam nessas questões alterações de cunho mais democrático e de acordo com o Estado de Direito.

No que se referem às questões ambientais, de preocupação ímpar e caráter urgente, as práticas de participação social, ganham aliado importante: o uso das tecnologias como possibilitador de uma cidadania capaz de alterar o direito, ou pelo menos, tomar novo rumo, em uma espécie de facilitador, buscando aliar a vontade da sociedade e a instantaneidade das redes.

As multidimensões da sustentabilidade provocam um manejo das diferentes formas que o desenvolvimento poderá ser realizado a fim de que os direitos fundamentais das futuras gerações sejam preservados e garantidos de maneira mais contundente possível. Sendo assim, essas diversas dimensões conversam entre si, e implicam no papel do cidadão responsável com determinadas práticas, elencando-se nessa ceara uma principal dimensão da sustentabilidade: a jurídico-política.

No que concerne à dimensão jurídico-política da sustentabilidade, e o resguardo do direito fundamental à democracia, preferencialmente direta, incluindo-se a utilização de novas tecnologias, precisa-se pensar como a cidadania ambiental pode auxiliar em questões de politicas 
públicas que sejam condizentes com a realidade de cada comunidade.

Diante do uso cada vez mais abrangente das novas tecnologias da informação e comunicação pelos membros da sociedade, pergunta-se em que medida a cidadania ambiental, através do instrumento digital, pode contribuir para o fortalecimento da democracia, alcançando níveis de participação direta em questões de elaboração e impulsionamento de politicas públicas relacionadas à conservação do meio ambiente?

Para responder ao presente questionamento, utiliza-se do método hipotético-dedutivo, partindo de um problema específico, oferecendo uma solução provisória e tentando criar soluções com vista a eliminar o erro através de questões, tais como: Existe um pleno direito à inclusão digital? Essa inserção dos indivíduos em ambiente online proporciona o impulsionamento de questões ambientais? Elenca-se para tratar da matéria, o método monográfico de procedimento de pesquisa, analisando casos em todos os aspectos que poderão ser representativos de outros semelhantes, propiciando entender como questões ambientais podem ser parâmetros para a efetivação da cidadania.

Para dar início ao estudo, se levará a discussão às origens e o conceito de cidadania, e qual o papel da mesma na construção do direito ou na sua efetivação. Em um segundo momento se passará a analisar exemplos de questões ambientais impulsionadas online e a possível construção de uma democracia participativa digital.

\section{CIDADANIA: ORIGEM E CONCEITO. COMO VISLUMBRAR O RECHAÇO A POLÍTICA E A CONSTRUÇÃO DO DIREITO A PARTIR DA CIDADANIA?}

Ao estudar os conceitos de cidadania e sua origem, deve-se 
levar em conta a tradição que circunda o tema, desde os primórdios pela noção de seu desenvolvimento na Grécia Antiga, para se chegar aos dias atuais, onde a globalização e a atuação das coisas em escala global fez transformar as concepções dos mais variados direitos, que agora se internacionalizam e tornam as práticas locais influenciadas pelo cenário mundial. Sendo assim, a noção de cidadania vem sofrendo mutações ao longo dos tempos, ampliando seu caráter já que apesar de estar arraigada nas lutas nacionais, o cidadão agora é cidadão do mundo.

Para que se possa verificar o alcance e o desenvolvimento do conceito de cidadania, Marshal, o divide em três partes: o civil, o político e o social, ditadas pela lógica, mas também pelo contexto histórico, que fez surgir às três partes, ora fundidas ora dissociadas. Por isso ele descreve (MARSHAL, 1967, p.63):

O elemento civil é composto dos direitos necessários à liberdade individual - liberdade de ir e vir, liberdade de imprensa, pensamento e fé, o direito à propriedade e de concluir contratos válidos e o direito à justiça. [...] Por elemento político se deve entender o direito de participar no exercício do poder político, como um membro de um organismo investido da autoridade política ou como um eleitor dos membros de tal organismo. As instituições correspondentes são o parlamento e conselhos do Governo local. O elemento social se refere a tudo o que vai desde o direito a um mínimo de bem-estar econômico e segurança ao direito de participar, por completo.

O desenrolar das noções de cidadania sempre esteve atrelado às formas de Estado, muitas vezes as formas de Estado Liberal e Social estiveram por ditar a possibilidade de participação do cidadão. Com a 
proliferação dos direitos civis e políticos no século XIX, e posteriormente a concretização dos direitos sociais que culminaram com o Estado de bemestar-social, atrelados desde então à cidadania, "[...] podemos identificar a partir da consolidação dos direitos sociais, também o surgimento dos direitos difusos e coletivos, onde o direito ambiental apresenta-se como propulsor dessa nova categoria de direitos que encontra-se em fase de consolidação" (ESTEVES, 2006, p.44).

Desde as concepções de luta de classe, derivada das rebeliões do proletariado ${ }^{1}$ em relação aos detentores dos meios de produção no perverso sistema capitalista denunciado por Marx, as práticas sociais ganharam avanço, rumo a uma cidadania que esteve norteada por ideias burgueses da época. "Sendo os direitos sociais, resultado de lutas derivadas dos antagonismos de classe, $[\ldots]$ como é construída a formulação teórica que os absorve na categoria de cidadania, ligada a uma noção jurídico-política norteada pelo arcabouço ideológico capitalista e liberal, e portanto burguês" (ESTEVES, 2006, p.44).

As noções mais clássicas de cidadania circundam pela proteção de direitos, ou tais como o direito a ter direitos, em uma espécie de educação para a reivindicação dos mesmos. A construção civil e política da cidadania tiveram como principal fonte um estabelecimento de Educação dos cidadãos para com seus direitos. Através da inserção de uma educação popular é que as lutas pelos direitos tiveram verdadeira ascensão, como refere Carvalho “A ausência de uma população educada

\footnotetext{
1 O proletariado passa por diferentes fases de desenvolvimento. Sua luta contra a burguesia começa com a sua existência. No começo, empenham-se na luta operários isolados, mais tarde, operários de uma mesma fábrica, finalmente, operários de um mesmo ramo da indústria, de uma mesma localidade, contra o burguês que os explora diretamente. (...) Mas, com o desenvolvimento da indústria, o proletariado não apenas se multiplica; comprime-se em massas cada vez maiores, sua força cresce e ele adquire maior consciência dela. Os interesses, as condições de existência dos proletários se igualam cada vez mais à medida que a máquina extingue toda diferença de trabalho e quase por toda parte reduz o salário a um nível igualmente baixo (Marx e Engels, 1998, p. 47).
} 
tem sido sempre um dos principais obstáculos à construção da cidadania civil e política" (CARVALHO, 2001).

Outro lado que não se pode deixar para traz é a correlação entre cidadania e Estado. Como referem Bolzan de Morais e Nascimento (2007, p.164), “[...] a cidadania moderna se desenvolveu à medida que as pessoas passavam a se sentir parte de uma Nação e de um Estado", juntamente com a educação para com os direitos a população pode engajar-se nas lutas do seu Estado.

Esse sentimento de pertencer a um Estado-nação está atrelado ao território geográfico, diferenciando estrangeiros e nacionais com perspectivas de cidadania em um dado local. "Historicamente, a cidadania foi concedida a restritos grupos de elite - homens ricos de Atenas e barões ingleses do século XIII - e posteriormente estendida a uma grande porção de residentes de um país" (VIEIRA, 2001, p.34-35), atrelando assim, cidadania a um direito de poder, de elite do território.

Segundo Vieira, existem dois tipos de conceito de cidadania, atrelados fundamentalmente em uma versão mais passiva, e outra mais ativa relativamente às questões de governo, como sucede (VIEIRA,1999):

Na primeira, o papel de cidadão é visto de forma individualista e instrumental, segundo a tradição liberal iniciada com Locke. Os indivíduos são vistos como pessoas privadas, externas ao Estado, e seus interesses são pré-políticos. Na segunda, prevalece uma concepção comunitarista oriunda da tradição da filosofia política proveniente de Aristóteles. Temos aqui uma cidadania ativa, e não mais passiva como no primeiro caso. Os indivíduos estão integrados em uma comunidade política e sua identidade pessoal é função das tradições e instituições comuns. 
Este tipo de teorização a cerca da cidadania contribui para o debate da nacionalização da cidadania, ora, pois conduzem a um ideal de como esta prática é instrumentalizada na vida dos indivíduos. $\mathrm{Na}$ primeira seção a cidadania é apolítica, e na segunda é instrumento que pode elaborar uma identidade coletiva, mas ambas se restringem a um âmbito de nacionalidade que é causa maior desse fenômeno.

Ao caracterizar-se sobre cidadania social e suas vantagens para a sociedade, “[...] cidadania social traz benefícios para as economias de mercado. Criando igualdade de oportunidades e reduzindo as profundas e permanentes diferenças de qualidade de vida entre os membros da sociedade" (ROBERTS, 1997). Essa é a cidadania que faz avançar, que projeta as condições para o futuro das gerações pela imposição de suas vontades enquanto fortalecedoras de direitos e preocupados com questões ambientais atinentes à democratização e efetivação da dimensão jurídicopolitica da sustentabilidade.

Ditando sobre a razão comunicativa de solução para os graves problemas que assolam a humanidade, Habermas visualiza o resgate de uma racionalidade comunicativa em esferas de decisão do âmbito da interação social que foram penetradas por uma racionalidade instrumental. Propõe um modelo ideal de ação comunicativa, em que as pessoas interagem e, através da utilização da linguagem, organizam-se socialmente, buscando o consenso de uma forma livre de toda a coação externa e interna que o direito e a política oferecem (HABERMAS, 1989). Essa seria a forma mais legítima de cidadania, livre de coações externas e instrumento apto a transformar o direito.

Habermas escreve o artigo "Soberania popular como procedimento" e conclui que há necessidade de ser resolvida a disputa entre direitos humanos e soberania popular. Habermas considera que 
somente um conceito do processo de soberania popular, pode pôr fim a essa disputa e reconhecer a origem em comum dos direitos humanos e da soberania popular. O princípio da soberania popular permite a mediação entre os direitos subjetivos fundamentais e o direito objetivo instituído pelo estado de direito (HABERMAS, 1989)

O referido autor provoca grande manifestação, acabando por dizer que somente a soberania do povo poderá dar conta de harmonizar os direitos dos indivíduos e fazer com que a sociedade viva em um constante diálogo com a politica, reformulando-a em diversos aspectos para que os interesses da população se sobressaiam na forma de normas e políticas públicas. Nesse aspecto o pensamento habermasiano se aproxima das práticas de cidadania, que nada mais são que conversas entre cidadãos que podem alterar o atual estágio das coisas, em especial no que tange ao direito ambiental e a preocupação com as gerações futuras, tal como $\operatorname{diz}$ (HABERMAS, 1989, p.102):

Uma vez que só pode manifestar-se na forma de leis gerais e abstratas, a vontade conjunta dos cidadãos é constrangida per se a uma operação que exclui todo interesse que não possa ser generalizado, admitindo apenas aquelas regulamentações que garantam liberdades iguais a todos. O exercício conforme as normas da própria soberania popular assegura, ao mesmo tempo, os direitos humanos.

A aposta é de que direito, política e cidadania possam andar juntas tais como em uma cooperação de vontades possam ser mais efetivas e tragam para a sociedade o que efetivamente o cidadão quer. Auspícios esses verificados não apenas pelo sufrágio, mas sim pela harmonização dos interesses dos indivíduos, ora engajados em agregar 
suas inquietações com a construção do direito e, portanto, consolidação de uma cidadania ampla, capaz de democratizar a política.

Apesar das expectativas de que o espaço social possa ser democratizado pela inserção dos indivíduos em pé de igualdade nas discussões politicas, é preciso também uma “[...] discussão acerca da singularidade de uma enorme periferia de sociedades que se formam ou que se transformam fundamentalmente a partir da expansão planetária do capitalismo moderno [...]" (SOUZA, 2006, p.11), criando grandes culturas que aparentemente são as únicas, mas que revelam por si só a emergência de um poder hegemônico dos grandes detentores econômicos de uma sociedade.

Em um país periférico como o Brasil, “[...] embora alternando períodos de democracia formal plena e autoritarismo, a expansão dos horizontes de participação política teve principalmente na expressão autônoma dos trabalhadores, seu limite e sua condição de existência [...]" (SOUZA, 2006, p.153) formando um padrão de cidadania periférica e institucionalizada.

Ou seja, as discrepâncias entre centro e periferia não são novidades da modernidade, mas sim possuem raízes históricas no capitalismo e na relação hegemônica Norte-Sul, que com o passar dos anos, eminentemente com um perfil econômico das relações dominaram as relações sociais, estabelecendo margens diferentes para denotar a opinião de cada cidadão, ou para que apenas seus valores se sobressaiam.

Ainda assim é preciso harmonizar os interesses dos cidadãos, posto que a igualdade já conferida pela Constituição Federal do Brasil em 1988, a Constituição Cidadã, preza por estabelecer. Evidentemente que a modernidade trouxe alguns avanços, permeada pelas novas tecnologias, onde "[...] um computador, realmente, não é 
pura tecnologia intelectual, um simples instrumento de representação do mundo, como postula uma parte dos cognotivistas, antes ele é um instrumento de transformação do mundo, material e humano" (LOJKINE, 2002, p.49).

Mesmo diante dos avanços há retrocessos, pois junto da revolução informacional estão muitos outros "vícios" que circundam e freiam a expressão de cidadania. Um exemplo disso é o consumo, pois "[...] se o direito de comprar um telefone celular, um tênis, um relógio da moda consegue silenciar ou prevenir entre os excluídos a militância política, o tradicional direito político, as perspectivas de avanço democrático se vêem diminuídas" (CARVALHO, 2001, p. 228). Nesse caso é o sistema representativo que vem falindo, e mostrando sua ineficácia no tratamento das desigualdades sociais, motivo pelo qual é preciso avançar, rumando por uma participação direta na democracia.

A consciência de um mundo, e da noção do ser humano para com as necessidades locais e mundiais aparece em meio a uma globalização dos saberes, das mentes e da informação. Segundo Milton Santos (2008, p. 59):

Isto significa saber o que o mundo é e como ele se define e funciona, de modo a reconhecer o lugar de cada país no conjunto do planeta e o de cada pessoa no conjunto da sociedade humana. É desse modo que se podem formar cidadãos conscientes, capazes de atuar no presente e de ajudar a construir o futuro.

Deste modo, cabe ao Estado educar para seus cidadãos conhecerem as realidades, e assim poderão ser transformadores do futuro através de uma comunicação coletiva, que pode influenciar as decisões políticas e romper com a apatia política. Aliando as novas tecnologias 
e as possibilidades de maior inclusão, ainda que não totalmente plenas e iguais pode-se chegar a uma nova roupagem para a cidadania, uma cidadania social que gera inclusão e cooperação do centro e da periferia.

Os instrumentos de participação vêm sendo otimizados, rumo a uma consolidação democrática da soberania popular, o que será estudado a partir da ótica ambiental de impulsionamento de questões relativas à conservação e preservação do meio ambiente.

\section{DEMOCRACIA PARTICIPATIVA DIGITAL: COMO O INSTRUMENTO DIGITAL TEM FEITO AVANÇAR E QUAL A CONDIÇÃO DE POSSIBILIDADE DE UMA CULTURA DA PARTICIPAÇÃO EM MATÉRIA AMBIENTAL?}

As concepções de consciência ambiental e cidadã podem ganhar nova roupagem com o surgimento da internet e da emergência de uma sociedade em rede cada vez mais interconectada em diversos aspectos, tornando os assuntos locais de um país interferentes em questões globais. Com isso a democracia poderá avançar, rumo a uma participação direta nas práticas de governo, impulsionadas online e como forma de efetivação de uma soberania do povo em matéria ambiental.

O alargamento de direitos sociais previstos pelas novas Constituições, em especial relacionado ao constitucionalismo latinoamericano, cumpre seu papel social revelando um Estado preocupado com questões sociais em detrimento dos clássicos direitos meramente individuais. Nesse entorno, os direitos ambientais aparecem como pertencentes a uma vertente moderna, pois tem preocupação com uma concepção coletiva e até inter-geracional. Ocorre que por vezes a tutela desses direitos perpassa por uma judicialização dos direitos sociais para 
sua efetivação, vez que o papel da cidadania está mitigado (ESTEVES, 2006, p.10-11):

Nesta busca pelo judiciário, como meio para solução dos conflitos sociais com vistas a dar consolidação à cidadania social, é possível identificar três tipos de contestação ou oposição alicerçadas em diferentes matrizes de interpretação e de ideologia. A primeira, de caráter jurídico-sociológico, entende que a procura pelo judiciário para resolução destes conflitos encontra obstáculo em questões ligadas à capacidade da tutela judicial para responder às demandas que dizem respeito a questões de eficácia de suas decisões, eficiência e acessibilidade ao sistema judicial. A segunda diz respeito a um posicionamento de caráter jurídico-ideológico que entende não ser tarefa do judiciário a resolução de tais conflitos. E faz parte de uma cultura jurídica que tem por objetivo impedir a discussão, o confronto e a tomada de decisão por parte do judiciário. A terceira, ligada a uma concepção político-ideológica entende que a judicialização dos conflitos sociais frustra a possibilidade de desenvolvimento das lutas populares pela reivindicação de direitos.

A medida em que o Estado frustra as expectativas e nada faz para a efetivação dos direitos sociais, mantendo-se inerte, as possibilidades de concretização da cidadania social também diminuem, pois de forma tradicional, a prevalência do poder judiciário dá ênfase às práticas de cidadania, que sozinhas fomentam políticas e direitos mas aliadas à força estatal ganham efetivação.

Não somente a força estatal, mas também a inserção da sociedade juntamente com as instituições pode levar a fomentar determinadas políticas públicas, inclusive em matéria ambiental, dando força às redes 
que se formam através do ambiente virtual pela participação online. Nesse sentido, o “[...] entendimento de que não são só os indivíduos ou grupos que têm força relevante influenciam as políticas públicas, mas também as regras formais e informais que regem as instituições"(SOUZA, 2006).

As políticas públicas são nesse contexto, "[...] a totalidade de ações, metas e planos que os governos traçam para alcançar o bemestar da sociedade e o interesse público [...] o bem-estar da sociedade é sempre definido pelo governo e não pela sociedade. Isto ocorre porque a sociedade não consegue se expressar de forma integral." (SEBRAE, 2008, p. 05). Justamente, na forma de expressão social e impulsionamento das demandas para o direcionamento de políticas públicas é que o ciberespaço vem se destacando.

O ciberespaço é então "[...] uma nova noção de espaço, em que o físico e o virtual se influenciam um ao outro, lançando as bases para a emergência de novas formas de socialização, novos estilos de vida e novas formas de organização social" (CARDOSO, 1998, p. 116), colocando alternativa de transformação do cenário local em global na perspectiva de novas formas de comunicação que almejem influenciar questões sociais, ambientais, de saúde, emprego, etc.

Não se pode deixar de falar nos níveis de pobreza e desigualdade que historicamente estiveram presentes na sociedade, gerando níveis de exclusão social "[...] que vem a ser, portanto, um traço constitutivo da classificação na qual se baseia o conceito estrutural de identidade social" (ZALUAR, 1997, p. 2), mas que com o advento das novas tecnologias de comunicação e informação podem estar ganhando novos delineamentos, no sentido de gerar maior integração social. Quando se fala no papel das políticas sociais para a democracia deve se ter em mente que (IVO, 2004, p.57): 
A política social é uma dimensão necessária da democracia nas sociedades modernas e está estreitamente ligada aos valores da equidade que fundam a legitimidade política e a concepção que as sociedades e os governos têm do seu projeto político e de seu destino.[...] as políticas sociais integram um sistema de ação complexo resultante de múltiplas causalidades e diferentes atores e campos de ação social e pública [...] que possibilitem a superação das desigualdades e o exercício pela cidadania [...]. Atuando no âmbito redistributivo, elas envolvem necessariamente relações de poder e são, portanto, conflitivas e qualificadoras da democracia e do projeto de inclusão social das sociedades.

O engajamento em políticas sociais, fomentado através da educação e propiciado pela inserção da sociedade em práticas online, é elemento essencial ao fortalecimento das democracias modernas e recentes como a do Brasil. Possibilitadas pelo pleno gozo da cidadania, a consequente diminuição de desigualdades e a integração da sociedade com o projeto democrático de participação direta.

Pois de acordo com a visão de Paulo Bonavides, a mais legitima forma de democracia seria aquela direta, revelando-se imperativa no constitucionalismo brasileiro, já que a "[...] democracia é como a liberdade, que, aliás, constitui o seu pressuposto básico: não sobrevive sem o oxigênio do debate que os pulmões do homem público respiram [...]" (BONAVIDES, 2004, p.19-20), posto que pelas liberdades plenas de confrontação de ideias revelar-se-ia a democracia em sua forma mais pura e adequada a realidade dos cidadãos.

Ainda assim é importante referir em que medida a inclusão digital tem tido força para angariar grande parte da sociedade e fazer 
com que os tais níveis de exclusão supracitados não se repitam no direcionamento de questões que reflitam interesse de apenas parte da população. Segundo o Cetic.br, através da pesquisa desenvolvida pelo TIC DOMICÍLIOS, revela que no ano de 2008 apenas $18 \%$ dos domicílios brasileiros possuía acesso a internet, número que foi alterado no ano de 2013 para 48\% (CETIC, 2014). Apesar do indicador não revelar tamanha expansão da internet é preciso ter em mente que muitos espaços públicos e escolas garantem o acesso à comunidade virtual, o que certamente avança em números de pessoas com acesso garantido.

O número de acessos à internet, apesar de não apresentar grandes indicadores, revela que com o passar dos anos e com a emergência da chamada sociedade em rede, o crescimento da inclusão online é caminho traçado, vez que a quantidade de usuários vem crescendo vertiginosamente. Dessa forma é importante referir que ao comparar os níveis de exclusão, muito tem se avançado nos últimos anos e com parcela significativa de apoio e debate em questões públicas propiciado em ambiente virtual. Dando ênfase a inclusão através da participação, define-se (GUERRA, 2012, p.42):

O princípio de participação assenta na perspectiva de que o combate à pobreza e à exclusão social é tanto mais efectivo quanto mais resulte de um processo amplamente participado pelas populações, onde as organizações de base associativa constituam instrumentos de reforço dos elos sociais. Este mesmo princípio parece caracterizar a própria estratégia de planeamento para o desenvolvimento no seu todo, na medida em que se vê surgir um novo contexto mais alargado, sistémico e integrado, que constitui hoje o terreno das políticas públicas - desenvolvimento local, luta contra a segregação e exclusão. 
Notoriamente a questão ambiental, como constitucionalmente prevista de forma expressa no artigo 225 da Carta de 1988, que dita "Todos têm direito ao meio ambiente ecologicamente equilibrado, bem de uso comum do povo e essencial à sadia qualidade de vida, impondo-se ao Poder Público e à coletividade o dever de defendê-lo e preservá-lo para as presentes e futuras gerações" (BRASIL,1988), ganha especial destaque nesse artigo, como forma de angariar a participação social em um direito/dever de todos, que possui um enfoque na preservação como fim último da vida humana. Nesse sentido, “[...] com base nesses elementos indissociáveis, a sustentabilidade, corretamente assimilada, consiste em assegurar, hoje, o bem-estar material e imaterial, sem inviabilizar o bemestar, próprio e alheio, no futuro" (FREITAS, 2012, p. 42).

Nessa ceara, no que tange ao desenvolvimento e preservação ambientais aliados às práticas online de cidadania, pode-se referir a petição virtual impulsionada pelo movimento Greenpeace no Brasil sobre o desmatamento zero. A referida iniciativa propõe que através da internet se dê vazão a um projeto de lei, que em seu texto institui o desmatamento zero no território nacional em relação às florestas nativas, tendo como principal exemplo a Floresta da Amazônia (DESMATAMENTO ZERO, 2015). Tal iniciativa, como pioneira vem acontecendo desde o ano de 2012, em que o projeto-lei já fora encaminhado para o Congresso Nacional a partir de 1.418 .670 assinaturas na petição online até nov/2015.

Nessa perspectiva, pode-se também iludir-se com o fato de que as petições são impulsionadas apenas por organizações institucionalizadas e não apenas como promoção de iniciativa cidadã. Ocorre que "[...] temse a perspectiva bottom-up, na qual as ideias emanam de baixo para cima, através da construção dos internautas. Esta nova fórmula traz a 
interatividade, principal benefício oferecido pela internet em relação a outras mídias" (RAMINELLI, 2014), dando ao internauta a possibilidade de exercer um ciberativismo em questões ambientais.

O ciberativismo nada mais é que uma releitura dos ativistas de movimentos sociais, agora inseridos na internet, que buscam nesse meio alternativas de maior visibilidade e expansão para suas lutas. "A novidade é a presença da Internet e do Celular, não apenas como um instrumento de comunicação, mas como uma forma de organização" (PINTO, 2011, p. 138) possibilitando grande mobilidade através da comunicação imediata e dinâmica (vertical e horizontal) aos movimentos.

Em matéria ambiental, o site Avaaz propõe dar lugar a demandas sociais, através de organização de movimentos e de petições online. Merecem destaque algumas de suas promoções, como a proposta de Redução dos Gases de Efeito Estufa em 40\% até o ano de 2030, com ajuda direta da população encaminharam mensagens a líderes internacionais por meio de enquetes e campanhas contundentes (DESTAQUES, 2015).

Outra importante iniciativa vem da Campanha Salvando Baleias de um Massacre, onde em nível mundial se pode expressar a cidadania, já que as questões ambientais ultrapassam os limites dos Estados, e colocam todo o planeta em um mesmo patamar de obrigações e de direitos. Sendo assim "Mais de 1,1 milhão de nós convencemos os políticos holandeses a assumir o compromisso de fechar os portos nacionais para esta carga" (DESTAQUES, 2015).

Dentre esses destaques elencados para análise, percebe-se que a dimensão jurídico-política da sustentabilidade, ecoa em um sentido de perspectiva de tutela jurídica de direito ao futuro, “ [...] como dever constitucional de proteger a liberdade de cada cidadão (titular de cidadania ambiental ou ecológica)" em especial no que tange a formação 
de um democracia preferencialmente direta, através do "[...] emprego intensificado das novas tecnologias e das redes sociais" (FREITAS, p. 67-69).

A vazão dada pela cidadania digital em matéria ambiental tem sido no sentido de conscientização da população e dos governantes em questões atinentes ao meio ambiente, posto que a democracia assim poderá ser fortalecida, mesmo que a passos lentos, mas sempre avançando. Em uma perspectiva que ainda não está no plano ideal de participação, posto que essa cultura encontra-se em pleno desenvolvimento, mas que sem duvidas tem sido alargada pelas novas tecnologias.

\section{CONCLUSÃo}

A possibilidade de concretização das recentes democracias modernas poderá estar aliada a práticas de cidadania, ampliadas pela inserção do Brasil e do mundo nas novas tecnologias da informação e comunicação. Assuntos atinentes a toda comunidade internacional que tem relevância expressa como nas questões ambientais podem ser um rumo importante para as inovações cidadãs online.

Ao tratar do tema de cidadania, é importante denotar que a sua expressão nos dias atuais vai muito além do direito de ser cidadão/ individuo da comunidade como ocorria na antiguidade onde apenas aos burgueses era conferido esse título. Hoje a cidadania está presente e acessível a grande parte da população que possui além do direito ao voto em eleições oficiais, o acesso aos meios digitais.

Quando utilizados de maneira correta, para fins de inclusão social e diminuição das diferenças sociais, o instrumento online poderá 
apresentar avanços em termos de democracia e soberania ambiental. Ao alcance de um clique, os indivíduos estão conectados e podem compartilhar das suas convicções, formar grupos e impulsionar petições e políticas públicas de forma online.

Como apresentado no texto, os desafios a uma inclusão digital ainda são muitos, mas nos últimos anos esse cenário tem ganhado especial avanço, ao passo que a tendência demostrada em pesquisas é de que esses números continuem aumentando. Aliado ao desenvolvimento da nação, as práticas virtuais poderão se tornar cada vez mais acessíveis e promissoras, dentro de um quadro de participação em questões ambientais internas e externas.

As petições online são hoje, em matéria ambiental, a expressão máxima daquilo que se consegue fazer com a utilização da internet por sujeitos conscientes e preocupados com o futuro da espécie humana. Deste modo, as democracias estão ganhando em participação direta, evoluindo para um grau mais maduro de existência, tornando-as mais sólidas e robustas frente ainda a um mundo tão desigual e disforme.

A questão de ciberativismo ambiental tem especial força e relevância, pois pode tornar assuntos interessantes a toda comunidade internacional mais acessíveis ao conhecimento e educação dos cidadãos, no sentido de formar pessoas preocupadas com as condições ambientais do planeta e fazer a diferença frente a um crescimento econômico perverso da globalização.

\section{REFERENCIAS}

BRASIL. Constituição da República Federativa do Brasil. Brasília, DF, Senado, 1998. 
BONAVIDES, Paulo. A constituição Aberta: temas políticos e constitucionais da atualidade, com ênfase no Federalismo das regiões. 3 ed. São Paulo: Editora Malheiros, 2006.

CARDOSO, Gustavo. Para uma sociologia do ciberespaço: comunidades virtuais em português. Oeiras, Portugal: Editora Celta, 1998.

CARVALHO, José Murilo de. Cidadania no Brasil: o longo caminho. Rio de Janeiro: Civilização Brasileira, 2001.

CETIC. Tic Domicílios, 2014. Disponível em: < http://data.cetic.br/ cetic/explore?idPesquisa=TIC_DOM $>$ Acesso em 10 nov 2015

DESMATAMENTO ZERO. Disponível em: $<$ http://www. desmatamentozero.org.br/ > Acesso em 11 nov 2015.

DESTAQUES. Avaaz. Disponível em: <http://www.avaaz.org/po/ highlights.php >. Acesso em 10 nov. 2015.

ESTEVES, João Luiz Martins. Cidadania e Judicialização dos conflitos sociais. IN: Revista de Direito Público. Londrina, v. 1, n. 2, p. 41-54, maio/ago. 2006.

FREITAS, Juarez. Sustentabilidade: direito ao futuro, belo horizonte: fórum, 2012.

GUERRA, Paula. Da exclusão social à inclusão social: eixos de uma mudança paradigmática. IN: RAS - Revista Angolana de Sociologia p. 91-110, 2012.

HABERMAS, Jürgen. Consciência moral e agir comunicativo. Rio de Janeiro: 
Tempo Brasileiro, 1989.

. Soberania Popular Como Procedimento: Um

Conceito Normativo De Espaço Público. Tradução Márcio Susuki. 1989.

IVO, Anete B. L. A reconversão do social: Dilemas da redistribuição no tratamento focalizado. São Paulo em Perspectiva, São Paulo, Vol. 18, no 2, p. 57-67, 2004.

LOJKINE, Jean. A Revolução informacional. Traduzido por José Paulo Netto. 3. ed. São Paulo: Cortez, 2002.

MARHALL, T. H. Cidadania, Classe Social e Status. Rio de Janeiro: Zahar Editores, 1967.

MARX, Karl; ENGELS, Friedrich. O manifesto do partido comunista. In: COGGIOLA, Osvaldo. (org.). Manifesto do partido comunista - Karl Marx e Friedrich Engels. São Paulo: Boitempo, 1998.

MORAIS, José Luiz Bolzan de; NASCIMENTO, Valéria Ribas do. A cidadania e a Constituição: uma necessária relação simbólica. In: Revista de Informação Legislativa. Brasília a. 44 n. 175 jul./set. 2007.

PINTO, Céli Regina Jardim. Movimentos Sociais 2011: estamos frente a uma nova forma de fazer politica? In: GOHN, Maria da Glória; BRIGUEL, Breno M. (orgs). Movimentos Sociais na Era Global. 2 ed. Petrópolis, Vorazes, 2014.

RAMINELLI, Francieli Puntel. Ciberativismo ambiental e o papel das petições online: análise de casos. In: Âmbito Jurídico, Rio Grande, XVII, n. 127, ago 2014. Disponível em: <http://ambito-Juridico.com. $\mathrm{br} / \mathrm{site} /$ ?n_link=revista_artigos_leitura\&artigo_id $=14256>$. Acesso em nov 2015. 
ROBERTS, Bryan. A dimensão social da cidadania. Revista Brasileira de Ciências Sociais, Belo Horizonte, a. 12, n. 33, fev. 1997.

SANTOS, Milton. Técnica, Espaço e Tempo. 5 ed. São Paulo: Editora Universidade de São Paulo,2008.

SEBRAE. Políticas Públicas: conceitos e práticas / supervisão por Brenner Lopes e Jefferson Ney Amaral; coordenação de Ricardo Wahrendorff Caldas - Belo Horizonte: Sebrae/MG, 2008.

SOUZA, Celina. Políticas públicas: uma revisão da literatura. In: Scielo Sociologias n.16 Porto Alegre jul./dez. 2006. Disponível em: $<$ http://dx.doi.org/10.1590/S1517-45222006000200003> Acesso em: 10 nov 2015.

SOUZA, Jessé. A Construção social da Subcidadania: para uma sociologia política da Modernidade Periférica. Belo Horizonte: UFMG; Rio de Janeiro: IUPERJ, 2006.

VIEIRA, Liszt. Cidadania Global e Estado Nacional. In: Dados vol.42 n.3 Rio de Janeiro, 1999. Disponível em: <http://dx.doi. org/10.1590/S0011-52581999000300001 > Acesso em 09 nov 2015.

\section{. Em torno do conceito de cidadania. In:}

ARGONAUTAS da cidadania: a sociedade civil na globalização. Rio de Janeiro: Record, 2001.

\section{ZALUAR, Alba. Exclusão E Políticas Públicas: Dilemas Teóricos} E Alternativas Políticas. Rev. bras. Ci. Soc., São Paulo, v. 12, n. 35, 1997. Disponível em: $<\mathrm{http} / / / \mathrm{www}$. scielo.br/scielo.php?script=sci_ arttext\&pid=S0102-69091997000300003-\&lng=pt\&nrm=iso $>$. Acesso em: 20 Jul 2007. Pré-publicação 
Como citar: PEREIRA, Marília do Nascimento. NASCIMENTO, Valéria Ribas do. O direito à inclusão digital: o papel da cidadania online em matéria ambiental para a construção de um democracia direta. Revista do Direito Público, Londrina, v. 12, n. 2, p. 130-154, ago. 2017. DOI: $10.5433 / 1980-511 X .2017 \mathrm{v} 12 \mathrm{n} 2 \mathrm{p} 130$

Recebido em: 22/07/2016

Aprovado em: 08/08/2017 